\title{
ОПЫТ ЛЕЧЕНИЯ МАСТАЛГИИ У ПАЦИЕНТОК С ДИСГОРМОНАЛЬНЫМИ ЗАБОЛЕВАНИЯМИ МОЛОЧНОЙ ЖЕЛЕЗЫ
}

Актуальность изучения дисгормональных заболеваний молочной железы (ДЗМЖ) обусловлена широким спектром их клинических проявлений и частой встречаемостью этой патологии, которая по данным различных авторов в общей популяции составляет 50-72\% $[7,9]$. Так, патологические изменения в молочных железах (МЖ) встречаются у 93,7-95\% пациенток с гинекологическими заболеваниями, у 80,6\% - с миомой матки в возрасте 30-45 лет, у $87,4 \%$ - с эндометриозом, у 32,1\% - с гиперпролактинемией, у 9-12\% лиц при гипофункции щитовидной железы [1, 4, 5, 10].

Наиболее частым клиническим проявлением ДЗМЖ является масталгия, или мастодиния - болезненное напряжение тканей. Это состояние, которое рассматривается как пограничное между нормой и патологией. Морфологическим субстратом мастодинии является гиперплазия железистых долек, венозный застой и отечность стромы МЖ $[1,5,8]$.

В зависимости от патогенетических механизмов различают циклическую и нециклическую масталгию [9], что требует различной врачебной тактики. Так, если при нециклической масталгии высокоэффрективно применение симптоматической терапии, то при циклической масталгии, которая является основным симптомом фиброзно-кистозной гиперплазии МЖ, необходим комплексный подход к коррекции гормонального гомеостаза, так как именно дисгормональные нарушения являются пусковым механизмом в ее патогенезе.

Однако на сегодняшний день все еще не существует четких рекомендаций и схем лечения циклической масталгии как при фрибрознокистозных мастопатиях, так и при других гинекологических заболеваниях $[1,5,7,12]$.

Отличительной особенностью МЖ является ее высокая чувствительность к гормональным колебаниям и прямая зависимость от психоэмоционального статуса женщины $[4,5]$. Следует отметить, что циклическая масталгия является также одной из самых распространенных жалоб в структуре предменструального синдрома у женщин позднего репродуктивного возраста. Высокий риск развития ДЗМЖ у каждой второй женщины обусловливают гинекологические нарушения, связанные с недостаточностью лютеиновой фазы, сопровождающиеся выраженным предменструальным синдромом [3].
По данным большинства авторов [6, 7, 13, 14], ведущей в патогенезе циклической масталгии является относительная или локальная гиперэстрогенемия. Локальный метаболизм эстрогенов в эпителии МЖ обеспечивают эстрадиолконвертирующие энзимы (сульфатаза, ароматаза, 17 $\beta$-гидроксистероиддегидрогеназа), запускающие процессы локального стероидогенеза из андрогенов, эстрона сульфата и эстрона, что в свою очередь фрормирует состояние местной гиперэстрогении и активирует патологическую пролиферацию [6]. При этом циклическая продукция прогестерона, которая усиливает дифференциацию протоковых и дольковых структур ткани МЖ, вступает в антагонизм с пролисреративным воздействием эстрадиола на эпителий железистой паренхимы [1-3]. Именно абсолютная или относительная прогестероновая недостаточность на фроне локальной гиперэстрогении сегодня рассматривается как один из основных причинных факторов развития масталгии у женщин, страдающих предменструальным синдромом, клиническим проявлением которого, как правило, является циклическая мастодиния.

Эстрадиол определяет большинство морфологических изменений в тканях МЖ, в частности стимулирует дифференцировку и развитие эпителия ее протоков, усиливает синтез ДНК и митотическую активность эпителия [5, 14]. Этот гормон стимулирует васкуляризацию и степень гидратации соединительной ткани, поэтому нарушение гормонального баланса по типу относительной гиперэстрогении вызывает отек и гипертрофию интралобулярной соединительной ткани, содержащей большое количество фибробластов и коллагеновых волокон.

В этой связи в обеспечении функционального состояния МЖ чрезвычайно важную роль играет соотношение концентрации эстрадиола и прогестерона именно в тканях железы. Прогестерон противодействует увеличению проницаемости капилляров, обусловленному эстрогенами, и уменьшает циклический отек соединительнотканной стромы. В пределах эпителия протоков прогестерон предотвращает пролиферацию и обеспечивает диффреренцировку на дольки и альвеолы [5, 9].

Нарушение соотношения уровня эстрадиола и прогестерона (по типу относительной гиперэстрогенемии) вызывает сначала
Т.Ф. ТАТАРЧУК

д.мед.н., профрессор, член-кор. НАМН Украины, заместитель директора по научной работе, заведующая отделением эндокринной гинекологии Института педиатрии, акушерства и гинекологии НАМН Украины

Л.В. КАЛУГИНА д.мед.н., ведущий научный сотрудник отделения эндокринной гинекологии

Института педиатрии, акушерства и гинекологии НАМН Украины

О.А. ЕФИМЕНКО к.мед.н., старший научный сотрудник отделения эндокринной гинекологии

Института педиатрии, акушерства и гинекологии НАМН Украины 


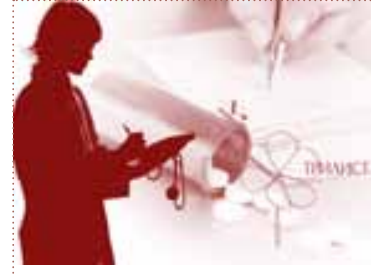

Включение в комплексную схему лечения ДЗМЖ фитопрепарата Тазалок ${ }^{\mathrm{TM}}$ повышает ее эффективность функциональные (мастодиния), а затем и морфологические изменения в МЖ (фиброзная реакция соединительной ткани, формирование кист, пролиферация эпителия и относительная регрессия альвеолярно-лобулярной ткани). Корреляция между мастодинией и мастопатией в настоящее время очевидна, причем большинство исследователей $[9,13,14]$ сходится во мнении на том, что одной из основных причин этих изменений является прогестероновая недостаточность. Дефицит этого гормона, независимо от причины, приводит к отеку соединительной ткани МЖ в результате увеличения капиллярного кровотока, что обусловливает болезненное напряжение МЖ. Затем возникают дистрофические изменения внутри реорганизованной соединительной ткани, что можно наблюдать на рентгенограммах в виде повышения маммографической плотности [1, 13].

Однако, как свидетельствует клиническая практика, применение только гестагенов для лечения масталгии на фоне ДЗМЖ хотя и патогенетически обоснованно, но не всегда оказывается эффрективным. В последние годы появляется все больше данных о роли провоспалительного звена в возникновении ДЗМЖ [14]. Под влиянием избытка простагландинов происходит локальная дилатация сосудов, отек, экссудация, сенсибилизация рецепторов к медиаторам боли (гистамину, брадикинину), понижая порог болевой чувствительности. По данным P. Rolland (1984), уровень простагландина $\mathrm{E}_{2}$ в крови больных мастопатией в 7-8 раз выше, чем у здоровых женщин.

Поэтому мы сочли целесообразным наряду с гестагенами включить в схему лечения препарат, регулирующий кровоснабжение, трофику, метаболизм и фрункциональное состояние ЦНС, а также обладающий гормонмоделирующим действием. В данном контексте представляет интерес фритокомплекс Тазалок ${ }^{\top м}$ («Про-Фарма») в виде настойки (1:10) смеси селективных фритомолекул корня лабазника шестилепесткового, свежего корня петрушки кудрявой, свежего корня сельдерея, травы подмаренника настоящего, травы ленка обыкновенного и цветков календулы. Растительные компоненты препарата Тазалок ${ }^{\mathrm{TM}}$ обладают широким спектром фрармакологических эфффектов. Биологически активные молекулы - флавоноиды, терпеноиды и фитостеролы (лабазник, ленок, петрушка и сельдерей) - устраняют состояние относительной гиперэстрогении, тем самым проявляя прогестеронмоделирующее действие. Салициловая кислота (лабазник, календула) оказывает противовоспалительное действие, блокирует синтез простагландинов, уменьшает отек и болевой синдром в ткани МЖ. Подмаренник также обладает выраженным противовоспалительным эфффектом, который обусловлен снижением синтеза интерлейкинов 2-го типа, спленоцитов и провоспалительных цитокинов (Churin A.A., 2006). Биологически активные молекулы календулы и подмаренника проявляют мягкое успокаивающее действие на ЦНС. Высокое содержание витаминов $\mathrm{B}_{1}, \mathrm{~B}_{2}$, К, РP, С, фолиевой кислоты в петрушке и В корне сельдерея оказывает общеукрепляющее действие на организм женщины и повышает ее адаптационные возможности. Мочегонный эффект, присущий лабазнику, петрушке, сельдерею, подмареннику, ленку и календуле, способствует уменьшению отека ткани МЖ.

Таким образом, фрармакологические эффекты, свойственные препарату Тазалок ${ }^{\mathrm{TM}}$, позволили включить его в комплексную схему лечения диффрузной фиброзно-кистозной мастопатии, сопровождающейся мастодинией.

\section{МАТЕРИАЛЫ И МЕТОДЫ ИССЛЕДОВАНИЯ}

В основу исследования положено наблюдение за 98 небеременными женщинами в возрасте от 25 до 39 лет с диффузной фрибрознокистозной мастопатией, сопровождающейся мастодинией, находившихся на амбулаторном лечении в отделении эндокринной гинекологии Института педиатрии, акушерства и гинекологии НАМН Украины. Все участницы исследования методом рандомизации были разделены на две группы. Основную группу составили 49женщин, которыеполучаликомбинированную терапию: исследуемый препарат Тазалок $^{\text {тм }}$ (настойка производства компании «Про-Фарма») по 30 капель за 30 мин до еды 3 раза в сутки и местную терапию трансдермальным 1-процентным гелем с микроионизированным прогестероном. Контрольную группу составили 49 пациенток, пролеченных по стандартной схеме: трансдермальный 1-процентный гель с микроионизированным прогестероном. Продолжительность лечения - 12 нед.

Проведена предварительная проверка данных на нормальность распределения при помощи критерия Шапиро - Уилка, согласно которому гипотеза о нормальности распределения не отклонялась (при $p=0,05$ ), и в таком случае использовались параметрические методы статистического анализа - непарный и парный двусторонний критерий Стьюдента. Для установления различия между процентным соотношением частоты определенного признака среди двух статистических выборок использовали специальный статистический метод - углового ф-преобразования Фишера. При множественном сравнении использован критерий Стьюдента с поправкой Бонферрони. 
Группы были сопоставимы по возрасту, данным экстрагенитального и гинекологического анамнеза (табл. 1, 2, 3).

В обеих группах пациентки имели отягощенный гинекологический анамнез с преобладанием воспалительных заболеваний гениталий и гиперпролиферативных процессов матки.

Анализ экстрагенитальной патологии выявил заболевания печени и желчевыводящих
ТАБЛИЦА 1. ВОЗРАСТНАЯ СТРУКТУРА ИССЛЕДУЕМЫХ ЖЕНЩИН*

\begin{tabular}{|c|c|c|c|c|c|c|}
\hline & \multicolumn{9}{|c|}{ Возраст, лет } \\
\hline Группы исследования & \multicolumn{2}{|c|}{$\mathbf{2 5 - 3 0}$} & \multicolumn{2}{|c|}{$30-35$} & \multicolumn{2}{|c|}{$35-39$} \\
\hline & $\mathbf{n}$ & $\%$ & $\mathbf{n}$ & $\%$ & $\mathbf{n}$ & $\%$ \\
\hline Основная $(\mathrm{n}=49)$ & 9 & 18,37 & 17 & 34,69 & 23 & 46,94 \\
\hline Контрольная $(\mathrm{n}=49)$ & 10 & 20,41 & 15 & 30,61 & 24 & 48,98 \\
\hline
\end{tabular}

ТАБЛИЦА 2. ЭКСТРАГЕНИТАЛЬНАЯ ПАТОЛОГИЯ В АНАМНЕЗЕ У ЖЕНЩИН ОБСЛЕДОВАННЫХ ГРУПП*

\begin{tabular}{|c|c|c|c|c|}
\hline \multirow{3}{*}{ Экстрагенитальная патология в анамнезе } & \multicolumn{4}{|c|}{ Группа женщин } \\
\hline & \multicolumn{2}{|c|}{ основная $(n=49)$} & \multicolumn{2}{|c|}{ контрольная $(n=49)$} \\
\hline & $\mathrm{n}$ & $\%$ & $\mathrm{n}$ & $\%$ \\
\hline Заболевания печени и желчевыводящих протоков & 26 & 53,06 & 24 & 48,98 \\
\hline Заболевания мочевыделительной системы & 9 & 18,37 & 8 & 16,32 \\
\hline Заболевания нервной системы & 13 & 26,53 & 17 & 34,69 \\
\hline Патология щитовидной железы & 16 & 32,65 & 19 & 38,77 \\
\hline Заболевания сердечно-сосудистой системы & 8 & 16,33 & 6 & 12,24 \\
\hline Заболевания опорно-двигательного аппарата & 2 & 4,08 & 3 & 6,12 \\
\hline
\end{tabular}

' $p>0,05$ во всех случаях

ТАБЛИЦА З. ГИНЕКОЛОГИЧЕСКИЕ ЗАБОЛЕВАНИЯ В АНАМНЕЗЕ У ЖЕНЩИН ОБСЛЕДОВАННЫХ ГРУПП*

\begin{tabular}{|c|c|}
\hline Гинекологические заболевания в анамнезе \\
\hline Воспалительные заболевания гениталий \\
\hline Эндометриоз \\
\hline Доброкачественные опухоли матки \\
\hline Доброкачественные опухоли придатков \\
\hline Доброкачественные изменения на шейке матки \\
\hline
\end{tabular}

протоков у 26 (53,06\%) женщин основной и у 24 (48,98\%) контрольной группы; патологию щитовидной железы у 16 (32,65 \%) пациенток основной и у 19 (38,77\%) контрольной группы, а также заболевания нервной системы у $13(26,53 \%)$ женщин основной и у 17 (34,69\%) контрольной группы.

В ходе исследования всем пациенткам проводили клинико-лабораторные обследования: общий анализ крови, биохимический анализ крови, общий анализ мочи, УЗИ МЖ, объективное обследование (гинекологический осмотр, пальпацию МЖ), осмотр онколога. Выраженность мастодинии (болевого синдрома) оценивали в динамике по визуально-аналоговой шкале (ВАШ) в баллах.

До начала лечения у всех женщин как основной, так и контрольной групп при пальпации МЖ определяли болезненность, диффрузные уплотнения в виде тяжистости, мелкой зернистости, пальпируемые в различных отделах, чаще в верхненаружных квадрантах. При осмотре онкологом у них не было выявлено узловых образований, увеличения лимфатических узлов.

При УЗИ были обнаружены различные формы диффузных изменений МЖ (табл. 4). При этом в обеих группах преобладали кистозные изменения.

\begin{tabular}{|c|c|c|c|}
\hline & \multicolumn{3}{|c|}{ Группа женщин } \\
\hline
\end{tabular}

" p > 0,05 во всех случаях

ТАБЛИЦА 4. ФОРМЫ ДОБРОКАЧЕСТВЕННЫХ ДЗМЖ, ВЫЯВЛЕННЫЕ ПРИ УЗИ*

\begin{tabular}{|c|c|c|c|c|}
\hline \multirow{2}{*}{ Формы ДЗМЖ } & \multicolumn{2}{|c|}{$\begin{array}{l}\text { Основная группа } \\
(\mathrm{n}=49)\end{array}$} & \multicolumn{2}{|c|}{$\begin{array}{l}\text { Контрольная группа } \\
\quad(\mathrm{n}=49)\end{array}$} \\
\hline & $n$ & $\%$ & $n$ & $\%$ \\
\hline $\begin{array}{c}\text { Дифрфузная фиббозно-кистозная гипер- } \\
\text { плазия с преобладанием фииброза }\end{array}$ & 17 & 34,70 & 16 & 32,65 \\
\hline $\begin{array}{c}\text { Дифффузная фибброзно-кистозная } \\
\text { гиперплазия с преобладанием кистозных } \\
\text { изменений }\end{array}$ & 20 & 40,8 & 19 & 38,78 \\
\hline Смешанная форма гиперплазии & 12 & 24,5 & 14 & 28,57 \\
\hline
\end{tabular}

p $>0,05$ во всех случаях
Клиническое наблюдение осуществлялось в динамике - до лечения, на 28-й, 56-й и 84-й день исследования.

\section{РЕЗУЛЬТАТЫ ИССЛЕДОВАНИЯ \\ И ИХ ОБСУЖДЕНИЕ}

В результате проведенных исследований наблюдалось значительное снижение степени выраженности масталгии как в основной группе, так и в группе контроля.

Следует отметить, что в основной группе снижение степени выраженности болевого синдрома наступало достоверно раньше в сравнении с монотерапией 1-процентным гелем с 
микроионизированным прогестероном в виде местных аппликаций. Уже после первого месяца терапии пациентки отметили позитивную динамику, о чем свидетельствует рисунок 1.

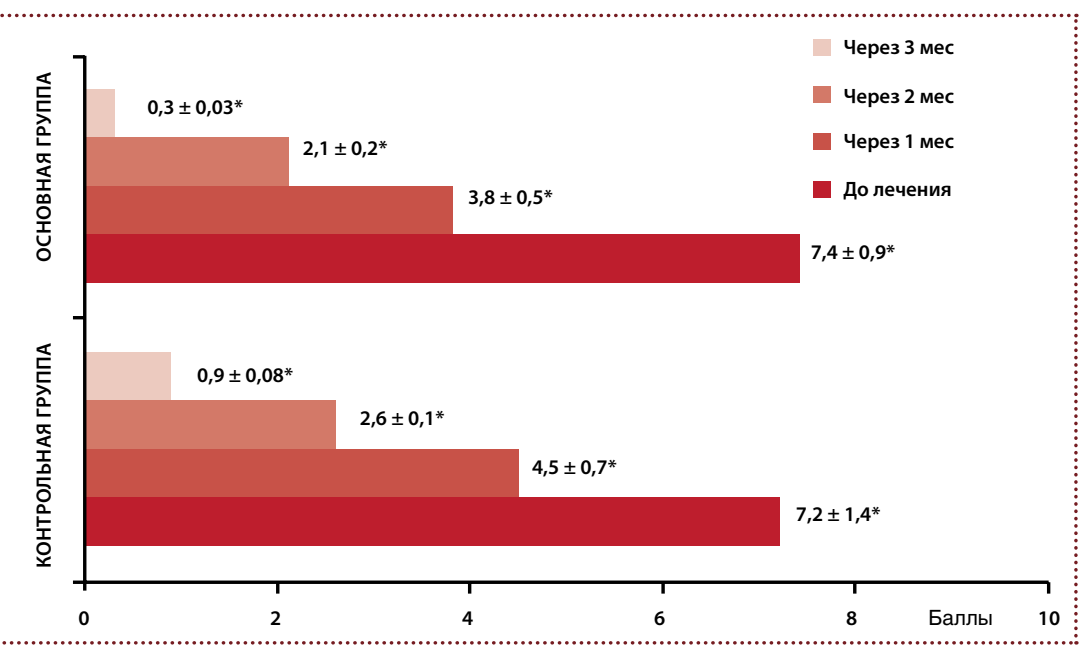
РИС 1.

ДИНАМИКА ВЫРАЖЕННОСТИ БОЛЕВОГО СИНДРОМА ПО ВАШ

* разница достоверна

относительно показателя до лечения $(\mathrm{p}<0,05)$

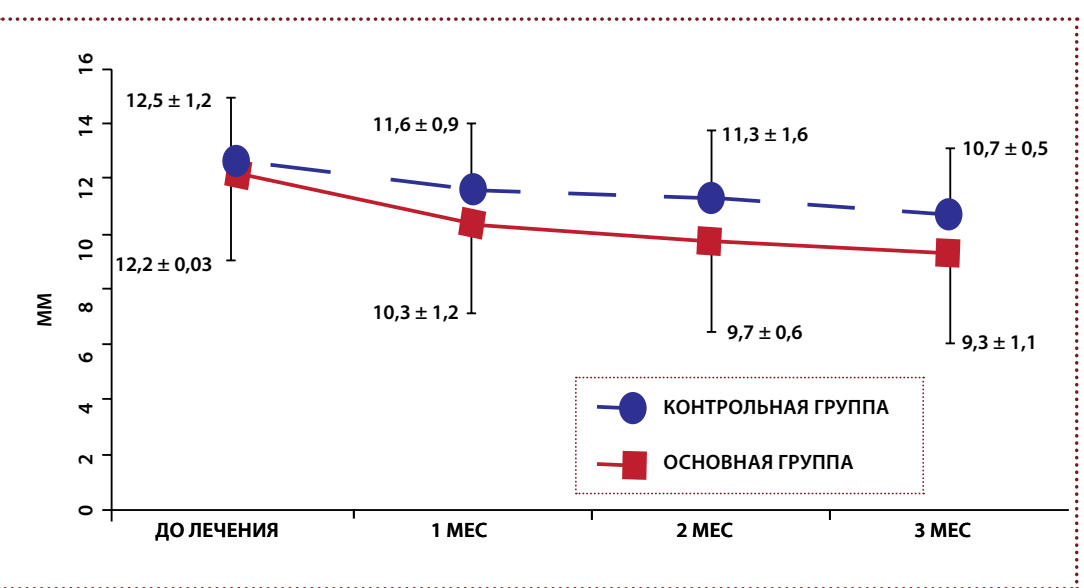

Большинство женщин как в основной (45, $91,84 \%)$, так и в контрольной $(36,73,47 \%)$ группах после проведенного лечения перестали жаловаться на масталгию.
PUC 2.

ДИНАМИКА СРЕДНЕГО ДИАМЕТРА БОЛЬШИХ КИСТ
По окончании исследования у 26 (53,06\%) пациенток основной группы и у 16 (32,65\%) контрольной наблюдали позитивную динамику пальпа」 торных признаков в виде уменьшения плотности, тяжистости и напряжения тканей МЖ, а также снижения болезненности при пальпации.

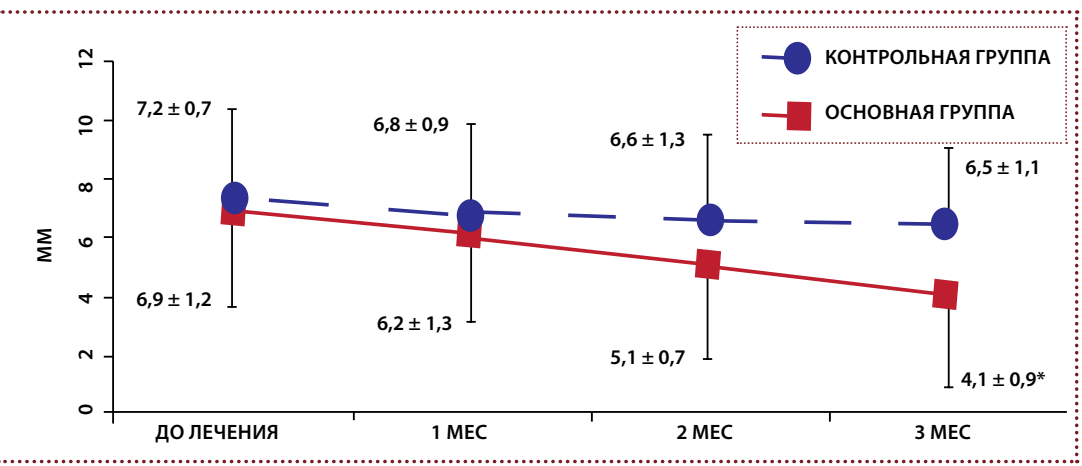

РИС 3.

ДИНАМИКА КОЛИЧЕСТВА МЕЛКИХ КИст до 5,0 мм

* разница достоверна относительно показателя до лечения $(p<0,05)$
По данным УЗИ МЖ после 3-месячного лечения у 16 (32,65\%) женщин основной группы и у 9 (18,37\%) контрольной группы выявлена положительная ультразвуковая динамика,
ТАБЛИЦА 5. ОЦЕНКА ЭФФЕКТИВНОСТИ ТЕРАПИИ ПАЦИЕНТКАМИ*

\begin{tabular}{|c|c|c|c|c|}
\hline \multirow{2}{*}{$\begin{array}{c}\text { Эффективность } \\
\text { лечения }\end{array}$} & \multicolumn{2}{|c|}{ Основная группа } & \multicolumn{2}{|c|}{$\begin{array}{c}\text { Контрольная } \\
\text { группа }\end{array}$} \\
\hline & $\mathrm{n}$ & $\%$ & $n$ & $\%$ \\
\hline $\begin{array}{c}\text { Лечение эфрфек- } \\
\text { тивно }\end{array}$ & 45 & 91,8 & 39 & 79,6 \\
\hline $\begin{array}{c}\text { Лечение не эфрфек- } \\
\text { тивно }\end{array}$ & 4 & 8,2 & 10 & 20,4 \\
\hline
\end{tabular}

* $p>0,05$ во всех случаях

что проявлялось снижением эхогенности железистых структур и уменьшением толщины паренхимы с 16,9 $\pm 1,6$ до 13,2 $\pm 1,1$ мм у женщин основной группы и с 16,3 $\pm 1,2$ до 14,2 $\pm 1,4$ мм контрольной группы ( $>$ >,05). Было отмечено уменьшение общего количества кистозных образований (рис. 2, 3).

ТАБЛИЦА 6. ОЦЕНКА ПЕРЕНОСИМОСТИ ПРЕПАРАТА ТАЗАЛОК ${ }^{\mathrm{TM} *}$

\begin{tabular}{|c|c|c|c|c|}
\hline \multirow{2}{*}{$\begin{array}{c}\text { Переносимость } \\
\text { препарата }\end{array}$} & \multicolumn{2}{|c|}{ Основная группа } & \multicolumn{2}{|c|}{$\begin{array}{c}\text { Контрольная } \\
\text { группа }\end{array}$} \\
\hline & n & $\%$ & n & $\%$ \\
\hline Хорошая & 47 & 95,92 & 45 & 91,84 \\
\hline Удовлетворительная & 2 & 4,08 & 4 & 8,16 \\
\hline $\begin{array}{c}\text { Неудовлетвори- } \\
\text { тельная }\end{array}$ & 0 & 0 & 0 & 0 \\
\hline
\end{tabular}

* $p>0,05$ во всех случаях

При этом в основной группе женщин, принимавших Тазалок ${ }^{\mathrm{TM}}$, достоверно уменьшилось количество мелких кист с 6,9 \pm 1,2 до 4,1 \pm 0,9 $(p<0,05)$ в отличие от группы контроля c 7,2 $\pm 0,7$ до $6,5 \pm 1,1$ ( $p<0,05)$.

При определении прогестерона во II фразе менструального цикла отмечалось более выраженное повышение его уровня (с 43,4 $\pm 7,2$ до $64,5 \pm 3,8$ нмоль/л) в основной группе по сравнению с показателями контрольной (с $46 \pm 7,6$ до 51,2 \pm 4,22 нмоль/л).

Эффрективность полученной комплексной терапии (табл. 5) как высокую оценили 45 $(91,8 \%)$ женщин, страдавших фриброзно-кистозной мастопатией с выраженным болевым синдромом. Монотерапия получила позитивную оценку у 39 (79,6\%) пациенток. Не удовлетворены результатами лечения остались 4 (8,2\%) больные в основной группе и $10(20,4 \%)$ в контрольной $\left(p_{1-2,3-4}>0,05\right)$.

Динамика показателей общеклинических лабораторных обследований (общего анализа крови, мочи, биохимического исследования крови) свидетельствовала об отсутствии общетоксического и сенсибилизирующего действий препарата Тазалок ${ }^{\mathrm{TM}}$. Существенных отличий в показателях до и после лечения не отмечено.

Переносимость комбинированной терапии (Тазалок ${ }^{\mathrm{TM}}+1$-процентный гель прогестерона местно) как хорошую оценили 47 (95,92\%) пациенток ( $p>0,05)$ (табл. 6).

Побочных эффректов при использовании исследуемого препарата отмечено не было. 


\section{ВЫВОД}

Результаты проведенного клинического исследования свидетельствуют, что использование многокомпонентного фитопрепарата Тазалок ${ }^{\mathrm{TM}}$ в комплексном лечении мастодинии у пациенток с ДЗМЖ повышает его эфффективность и является патогенетически обоснованным.

\section{ЛИТЕРАТУРА}

1. Винклер У.Х., Шиндлер А.Е., Бринкман Ю.С. и др.

Циклическая прогестиновая терапия мастопатии и мастодинии. - 2000. - С. 19-29.

\section{2. Озерова О.Е.}

Ультразвуковая маммография (дисплазия и возрастные особенности молочной железы в норме) // Акушерство и гинекология. - 2004. - № 6. - С. 58-73.

\section{3. Радзинский В.Е., Ордиянц И.М.}

Предменструальный синдром и доброкачественные дисплазии грудных желез: реалии и перспективы // Здоровье женщины. - 2011. - № 1 (57). - С. 71-75

4. Татарчук Т.Ф., Ефименко О.А., Васильченко Л.А., Яроцкая Н.В.

Энзимотерапия в лечении циклической мастодинии у женщин с дисгормональными заболеваниями молочных желез // Здоровье женщины . -2010. - № 5 (51). C. $58-61$.

5. Татарчук Т.Ф., Ефименко О.А., Тутченко Т.Н. Мастодиния на фоне хронического стресса у женщин активного репродуктивного возраста // Здоровье женщины. - 2009. - № 10 (46). - С. 50-54.
6. Татарчук Т.Ф., Сольский Я.П.

Эндокринная гинекология (клинические очерки). Ч. 1. К.: Заповіт, 2003. - 303 с

7. Серов В.Н., Прилепская В.Н., Овсяникова Т.В. Гинекологическая эндокринология. - М.: МЕДпресс-инфрорм, 2006. -520 C.

8. Bauman R.A., Kant G.J.

Chronic suistain stress increases level of auterior pituitary prolactin mRNA // Pharmacol. Biochem. Beha. - 2000. -

Vol. 67. - P. 423-431.

9. Bieber E.J., Sanfilippo J.S., Horovitz I.R.

Clinical Gynecology. 2006, ELSEVIER, 1003.

10. Breckwoldt M. et al.

A new treatment option for hyperprolactinaemic disorders. XI Annual Meeting of the European Society of Human Reproduction and Embriology. - June 30, 1995. - Hamburg. P. 24.

11. Churin A.A., Masnaia N.V. et al.

Effect of Filipendulaulmaria extract on immune system of CBA/CaLac and C57BI/6 mice // VoprPitan. 2006; 75 (2): 22-6.

12. Dittmar F.-W., Luh W.

Treatment of fibrocystic mastopathy // Int. J. of

Experimental and Clinical Chemotherapie. - Vol. 5, № 1. 1999. - P. 11-22.

13. Leucht W.

Teaching Atlas of breast ultracound. Stuttgart:

ThiemeVerlag. - 1992.

14. Manassiev N., Whitehead M.I.

Female Reproductive Health, The Parthenon Publishing Group., 2004. - P. 195.

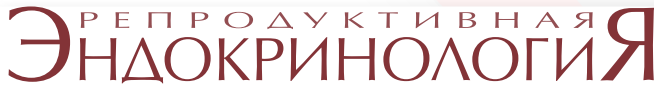 АССОЦИАЦИЯ ГИНЕКОЛОГОВ-ЭНДОКРИНОЛОГОВ УКРАИНЫ}

\section{Oforibnremer korkype!}

Учитывая роль становления

репродуктивной системы и особенности течения

пубертатного периода у девочек в генезе развития нарушений репродуктивного здоровья и формирования

гормонозависимых предопухолевых и опухолевых

заболеваний у женщин,

\section{объявляется конкурс на лучшую научную роботу}

\section{по проблемам гинекологии детского}

\section{и подросткового возраста в двух номинациях:}

Аналитический обзор по проблеме

Результаты собственных клинических исследований 